\title{
Comparative Study of the Antioxidant Activity of Two Popular Green Tea Beverages Available in the Local Market of Saudi Arabia
}

\author{
Ulfat M. Omar*, Ayat M. Shorbaji, Entesar M. Arrait, Tasneem D. Al Agha, \\ Hala F. Al-Marzouki, Huda A. Al Doghaither, Ayat B. Al-Ghafari \\ Department of Biochemistry, Faculty of Science, King Abdulaziz University, Jeddah, KSA \\ Email: "uomer@kau.edu.sa
}

Received 17 February 2016; accepted 14 June 2016; published 17 June 2016

Copyright $(2016$ by authors and Scientific Research Publishing Inc.

This work is licensed under the Creative Commons Attribution International License (CC BY). http://creativecommons.org/licenses/by/4.0/

c) (i) Open Access

\begin{abstract}
Antioxidants have numerous applications due to their multiple roles in diminishing harmful effects of oxidative stress. The objective of this work was to highlight the importance of green tea by evaluating the antioxidant activity of the most popular green tea brands in Saudi Arabia, Lipton and Rabea. To our knowledge, no studies have so far been done to estimate the antioxidant activity of these brands. To determine the antioxidant activities of these two brands, $10 \mathrm{mg} / \mathrm{ml}$ of each brand was extracted and their total phenolic content (TPC), 2,2-diphenyl-1-picrylhydrazyl (DPPH) radical scavenging activity, hydrogen peroxide scavenging activity, ferric reducing power and ferrous ion chelating effect were measured. The TPC of Lipton tea was $678.7 \mu \mathrm{g}$ of gallic acid equivalents (GAE)/10mg, whereas in Rabea tea, the TPC was $647.1 \mu \mathrm{g}$ GAE/10mg. The presence study indicated that there were no significant differences in total phenolic contents and the percentage inhibition as shown in DPPH and $\mathrm{H}_{2} \mathrm{O}_{2}$ assays among Lipton and Rabea green teas. Moreover, it was found that all assays have exhibited high antioxidant activity in both green teas. In conclusion, our study showed evidence for evenness and stability of the antioxidant activity of the two commercial green teas available in the markets of Saudi Arabia. Continued researches are needed to further the current knowledge on the health-promoting effects of this popular beverage using different supplements by different mechanisms.
\end{abstract}

\section{Keywords}

Green Tea, Polyphenols, Antioxidants, Radical Scavenging Activity, Total Phenolic Content

\footnotetext{
${ }^{*}$ Corresponding author.
}

How to cite this paper: Omar, U.M., Shorbaji, A.M., Arrait, E.M., Al Agha, T.D., Al-Marzouki, H.F., Al Doghaither, H.A. and Al-Ghafari, A.B. (2016) Comparative Study of the Antioxidant Activity of Two Popular Green Tea Beverages Available in the Local Market of Saudi Arabia. Natural Science, 8, 227-234. http://dx.doi.org/10.4236/ns.2016.86027 


\section{Introduction}

Tea is the most widely consumed drink in the world after water. It has been cultivated and consumed for more than 2000 years. Tea comes from the leaves of two classes of Camellia sinensis plant: assamica and sinensis, which originate in China and Southeast Asia [1] [2]. Tea has complex structure, which contains polyphenols, amino acids, proteins, alkaloids, minerals, carbohydrates, volatile compounds and trace elements [3]. Due to the presence of polyphenols, many scientific studies have proved the health benefits of tea such as anti-carcinogenic, anti-oxidant, anti-aging, anti-mutagenic, anti-viral, anti-bacterial, and anti-inflammatory properties [4] [5]. Tea can be classified according to the processing procedures into black, green and oolong tea. The percentage of each type of tea produced and consumed in the world is: $78 \%$ black, $20 \%$ green and $2 \%$ oolong tea [6]. Among the different types of tea, green tea is now preferred as it has much more positive health benefits in comparison to other natural products [7]. Green tea is produced by streaming fresh leaves to prevent catechin oxidation by polyphenol oxidase. With no fermentation, green tea leaves preserve their color and almost all of their catechin content [8], and therefore have greater antioxidant potential than oolong and black tea, which are semi-fermented or fully fermented, respectively [9]. Green tea is rich in the flavonol group of polyphenol called catechin. Catechins act as antioxidants by sequestering metal ion and by scavenging free radicals that can damage DNA and contribute to cancer, metabolic dysfunctions, coagulation and atherosclerosis [10] [11]. The six major catechins known to exhibit biological activity are (+)-catechin (C), (-)-epicatechin (EC), (-)-epigallocatechin (EGC), $(-)$-gallocatechin gallate (GCG), (-)-epigallocatechin gallate (EGCG) and (-)-epicatechin gallate (ECG) [12]. Epigallocatechin gallate is the most plenty catechin in green tea, which accounts for $50 \%$ of the total catechins [8]. The antioxidant properties of green tea and its component of catechins were detected in many diseases associated with reactive oxygen species (ROS), such as cancer and neurodegenerative diseases. Many epidemiological studies have been conducted to show that green tea can provide protection against several cancers such as breast, prostate, bladder, ovarian, colorectal, esophageal, lung, pancreatic, and skin cancer [8]. Moreover, green tea has been found to provide protection against age-associated neurodegenerative and many other pathological diseases such as Alzheimer's disease, Parkinson's disease and ischemic damage [1]. Thus, the purpose of our research was to compare the total phenolic content, radical scavenging activity and metal chelation antioxidant activity of two popular green tea brands from local Saudi markets (Lipton classic green tea and Rabea green tea), by using several spectrophotometric methods. According to our knowledge, this is the first study to estimate antioxidant activity of the most common green tea brands available in the Saudi markets.

\section{Materials and Methods}

\subsection{Chemicals}

Chemicals used were as follows: Folin-Ciocalteu's phenol reagent, anhydrous sodium carbonate, 2,2-diphenyl1-bicrylhydrazyl, ethanol, ascorbic acid, and phosphate buffered saline, and they were purchased from Fisher Scientific (Loughborough, UK). Hydrogen peroxide, phosphate buffer, potassium ferricyanide, trichloroacetic acid (TCA), ferric chloride, ferrous chloride, ferrozine and ethylenediaminetetraacetic acid (EDTA) were purchased from Sigma-Aldrich Chemical Co. (Pool, UK).

\subsection{Samples and Extract Preparation}

Two different brands of commercial tea, purchased from the local market (Lipton classic green tea and Rabea green tea), were used in this study. Both tea samples were prepared according to the traditional method, to measure their antioxidant activity using different methods. Each sample was prepared by adding hot water to tea leaves $(10 \mathrm{mg} / \mathrm{ml})$, then the mixture was kept at room temperature for 10 minutes before starting the experiments. The reducing ability of each sample was measured at different concentrations $(2.5,5$, and $10 \mathrm{mg} / \mathrm{ml})$.

\subsection{Determination of Total Phenolic Content (TPC)}

TPC was determined according to the Folin-Ciocalteu procedure used by [13]. A sample of $0.5 \mathrm{ml}(10 \mathrm{mg} / \mathrm{ml})$ was mixed with $5 \mathrm{ml}$ of deionized water and $0.5 \mathrm{ml}$ of Folin-Ciocalteu's reagent was added to all samples. The tubes were incubated at room temperature for 5 minutes. After that, $1 \mathrm{ml}$ of $2 \%$ sodium carbonate $(\mathrm{w} / \mathrm{v})$ was added to all test tubes and incubated in dark place for one hour before the absorbance was measured by spectrophotometer at $750 \mathrm{~nm}$. 


\subsection{DPPH Radical Scavenging Assay}

Inhibition of DPPH radical was measured according to [14] method. First, $250 \mu \mathrm{l}$ of ethanol (99.5\%) was added to $250 \mu$ lexperimental sample and incubated with $62.5 \mu \mathrm{l}$ of DPPH solution. The samples were incubated in the dark for one hour at room temperature and the absorption was measured at $517 \mathrm{~nm}$ using spectrophotometer [14]. The experiment was performed in triplicate. Radical scavenging activity was expressed as inhibition percentage and was calculated using the following equation:

$$
\% \text { inhibition }=[(\mathrm{AB}-\mathrm{AA}) / \mathrm{AB}] \times 100
$$

where: $\mathrm{AB}=$ absorption of blank sample.

$\mathrm{AA}=$ absorption of sample.

\subsection{Hydrogen Peroxide Assay}

Hydrogen peroxide was measured according to the procedure described previously by [15]. Hydrogen peroxide $(40 \mathrm{mM})$ was prepared in phosphate buffer saline at $\mathrm{pH} 7.4(\mathrm{v} / \mathrm{v})$, and $0.6 \mathrm{ml}$ of the prepared buffer was added to all test tubes, followed by $1 \mathrm{ml}$ of each sample and incubated at room temperature for 10 minutes. Finally, the absorbance was measured by uv-spectrophotometer at $230 \mathrm{~nm}$. Radical scavenging activity was expressed as inhibition percentage and was calculated by the following equation:

$$
\% \text { inhibition }=[(\mathrm{AB}-\mathrm{AA}) / \mathrm{AB}] \times 100
$$

where: $\mathrm{AB}=$ absorption of blank sample.

$\mathrm{AA}=$ absorption of sample.

\subsection{Reducing Power Assay}

Reducing power activity was determined according to [16] procedure. First, $1 \mathrm{ml}$ of each sample was mixed with $2.5 \mathrm{ml}$ of phosphate buffer $\mathrm{pH} 6.6$ and $2.5 \mathrm{ml}$ of potassium ferricyanide (1\%) and then incubated in water bath at $50^{\circ} \mathrm{C}$ for 30 minutes. $2.5 \mathrm{ml}$ of $10 \%$ trichloroacetic acid (TCA) was added for acidifying the mixtures,. The acidified mixture was centrifuged at $6000 \mathrm{rpm}$ for 10 minutes at $10^{\circ} \mathrm{C}$. After that, $2.5 \mathrm{ml}$ of the supernatant was mixed with $2.5 \mathrm{ml}$ of deionized water and $0.5 \mathrm{ml}$ ferric chloride (1\%). At the end, the absorbance was measured at $700 \mathrm{~nm}$ by spectrophotometer.

\subsection{Ferrous Ion Chelating Assay (FIC)}

The ferrous ion chelating effect was investigated according to [17] method. First, $5 \mu \mathrm{l}$ of each sample was mixed with $50 \mu \mathrm{l}$ of ferrous chloride $(2 \mathrm{mM})$ and $1.5 \mathrm{ml}$ of distilled water, and then the mixture was vortexed for 30 seconds. After that, $100 \mu \mathrm{l}$ of ferrozine $(5 \mathrm{mM})$ was added to the mixture then incubated at room temperature for 10 minutes. Finally, the absorbance was measured at $562 \mathrm{~nm}$ by spectrophotometer. In this experiment, $0.01 \%$ EDTA solution was used as a positive control. Ferrous ion chelating capacity was calculated by the following equation:

$$
\text { Chelating effect } \%=[(\text { A control }- \text { A sample }) / \text { A control }] \times 100
$$

\subsection{Statistical Analysis}

Statistical analysis was performed using GraphPad Prism 6.0andall data were expressed as the means \pm SD of three independent experiments carried out in triplicate. Analysis of variance was performed by unpaired t-test. The results with $P<0.05$ were considered statistically significant.

\section{Results}

\subsection{Total Phenolic Content (TPC)}

Total phenolic contents of Lipton and Rabea green tea were expressed as gallic acid equivalent. The results showed that the content of polyphenols for Lipton and Rabea were 678.7 and $647.1 \mu \mathrm{g}$ of gallic acid/10mg of 
tea, respectively. Therefore, there were no significant differences in the polyphenolic contents between the experimental tea types.

\subsection{DPPH Radical Scavenging Activity}

DPPH assay is used to evaluate the free radical scavenging activity of hydrogen donating antioxidants in many plant extracts. DPPH is a stable free radical with a dark violet color. This method is based on the principle that DPPH accepts a hydrogen atom from the antioxidant, resulting in the reduction of DPPH to DPPH2, the violet color changes to yellow with a consequent decrease in absorbance at $516 \mathrm{~nm}$. The efficiency of the antioxidant compound is measured by its ability to change color.

The percentage of inhibition caused by Lipton was $94 \%$ for the concentration of $10 \mathrm{mg} / \mathrm{ml}$, while the scavenging activity of Rabea tea was $92 \%$ at the same concentration as shown in Figure 1. These results demonstrated that Lipton and Rabea have the ability to scavenge free radicals. Therefore, both have the same high antioxidant activity.

\subsection{Scavenging of Hydrogen Peroxide $\left(\mathrm{H}_{2} \mathrm{O}_{2}\right)$}

Hydrogen peroxide has the ability to diffuse across biological membranes and can be generated in tissues during oxidative processes. There are three ways to produce $\mathrm{H}_{2} \mathrm{O}_{2}: 1$ ) by dismutation of the superoxide anion radical (enzymatic superoxide dismutase SOD), 2) by dismutation of the superoxide anion radical (non-enzymatic) or 3) by 2-electron reduction of molecular oxygen [18]. $\mathrm{H}_{2} \mathrm{O}_{2}$ assay measured the ability of phenolic compounds to act as an electron donor at $320 \mathrm{~nm}$ at which $\mathrm{H}_{2} \mathrm{O}_{2}$ was converted to $\mathrm{H}_{2} \mathrm{O}$.

The percentage of inhibition caused by Lipton was $67 \%$ for the concentration of $10 \mathrm{mg} / \mathrm{ml}$, while the scavenging activity of Rabea at the same concentration was 69\%. As shown in Figure 2, there was no significant difference in the percent inhibition values between Lipton and Rabea green tea at concentration of $(10 \mathrm{mg} / \mathrm{ml})$ $(P>0.05)$.

\subsection{Reducing Power Assay}

The most widely used method for total antioxidant capacity is the reducing power assay. The aim of this assay is to measure the reduction of ferric $\left(\mathrm{Fe}^{3}\right)$ to ferrous $\left(\mathrm{Fe}^{2}\right)$ ion [19]. Flavonoids act as antioxidants that are one of the components of green tea which they provoke the formation of less reactive species by electron donating via reducing power assay estimation. The results in this study showed an increase in the reductive ability of Lipton and Rabea green tea with an increase in the absorbance at $700 \mathrm{~nm}$ as shown in Table 1 . The reductive activities

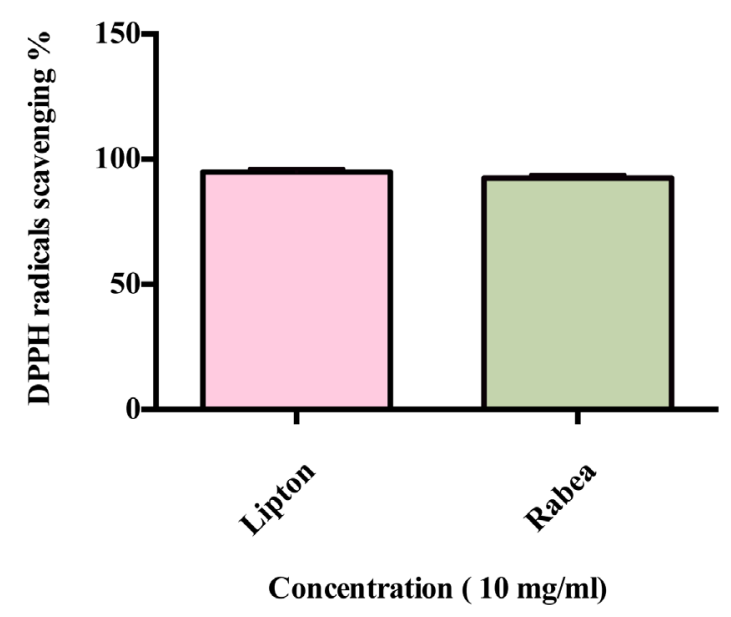

Figure 1. Radical scavenging activity by Lipton and Rabea green tea. Concentration of both components was $10 \mathrm{mg} / \mathrm{ml}$. The value expressed as means \pm SD (n $=3$ ). Compression of means was made using unpaired t-test $(P>0.05)$. 


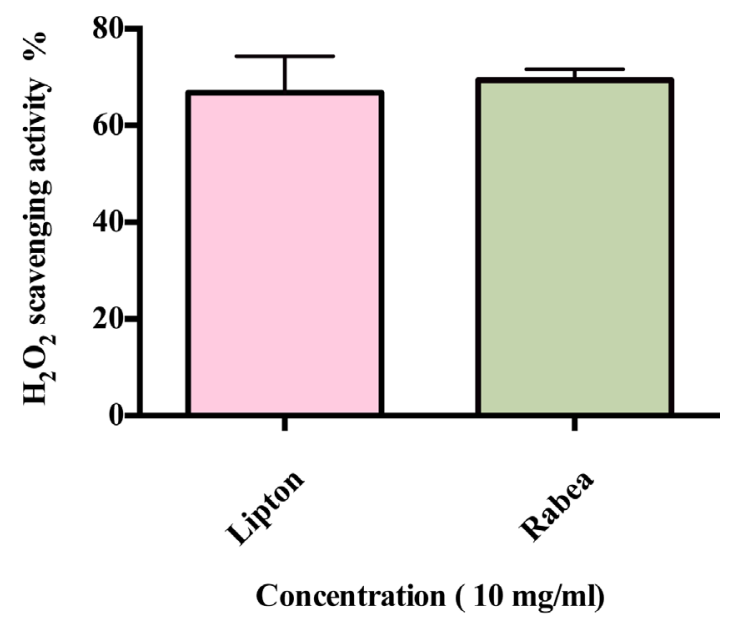

Figure 2. $\mathrm{H}_{2} \mathrm{O}_{2}$ scavenging activity of Lipton and Rabea green tea. Concentration of both components was $10 \mathrm{mg} / \mathrm{ml}$. The value expressed as means \pm SD $(n=3)$. Compression of means was made using unpaired t-test $(P>0.05)$.

Table 1. Reducing power activity in both brands.

\begin{tabular}{cccc}
\hline Concentrations $(\mathbf{m g} / \mathbf{m l})$ & $\mathbf{2 . 5}$ & $\mathbf{5}$ & $\mathbf{1 0}$ \\
\hline Lipton & 0.2 & 0.4 & 0.5 \\
Rabea & 0.18 & 0.38 & 0.5 \\
\hline
\end{tabular}

corresponding to concentration ranges $(2.5,5$ and $10 \mathrm{mg} / \mathrm{ml})$ of Lipton and Rabea green tea are shown in Figure 3 . The reducing activity revealed that there is no significant difference was observed between the two brands ( $P$ values were $0.6,0.5$ and 0.4 , respectively).

\subsection{Ferrous Ion Chelating Activity (FIC)}

Iron is considered as a reactive metal being able to catalyze oxidative damage in cell [20]. In the presence of an antioxidant, the formation of the ferrous ion-ferrozine complex is inhibited. Therefore, chelation ability can be an indicator of an antioxidant activity of green tea.

The chelation effect of Lipton and Rabea green tea measures the efficiency of the compounds in them that compete the ferrozine for ferrous ions. Figure 4(a) shows that both components chelate ferrous ion at $10 \mathrm{mg} / \mathrm{ml}$ with no significant differences between each other. In comparison with EDTA, which was used as a standard metal chelating agent in this study, the ferrous chelating activity of EDTA was 96\% while, for Lipton and Rabea green tea were 83\% and 84\% respectively, as shown in Figure 4(b).

\section{Discussion}

Polyphenols are a class of chemical constituents with one or more hydroxyl groups associated to the aromatic arene (phenyl) ring. Consequently, they are considered as one of the most potent antioxidative compounds that contribute to the antioxidant activity [21]. Hence, it is important to quantify polyphenol content and to estimate its contribution to antioxidant activity. Our results showed that the concentration of total phenol content was high in both brands but there were no significant differences between them. This result may be referred to the high antioxidant activity of tea catechins, which are mainly found in green tea. Catechins (flavan-3-ols) belong to the flavonoid family. Flavan-3-ols considered the greatest antioxidant contribution to green tea and represented for approximately $68 \%$ of its total antioxidant potential [22]. The main green tea catechins are Epicatechin (EC), epigallocatechin (EGC), epicatechin gallate (ECG) and epigallocatechin gallate (EGCG) [23]. In general, Epigallocatechin gallate is the most powerful catechins in tea and it is responsible for the majority of the biological activity of green tea. It is well known that green tea has greater total catechins than black tea due to 


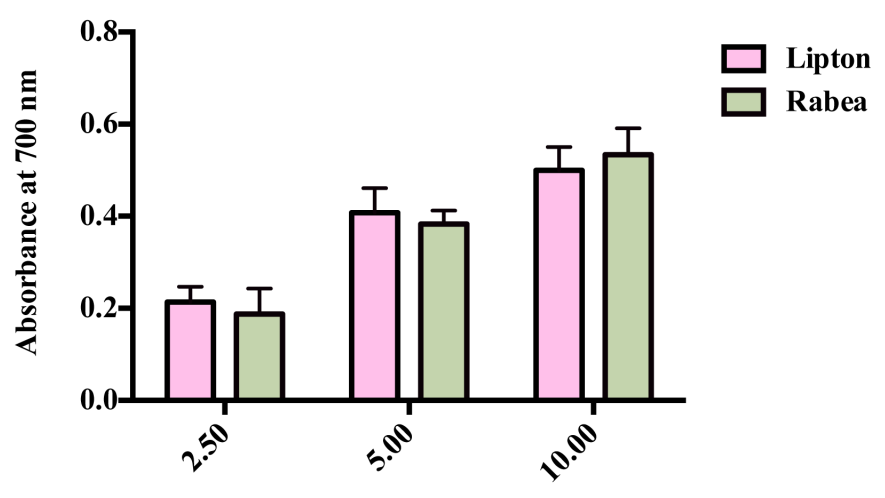

Concentration (mg/ml)

Figure 3. Reducing power of different concentration from Lipton green tea and Rabea green tea. The value expressed as means $\pm \mathrm{SD}(\mathrm{n}=3)$. Compression of means was made using unpaired t-test $(P>0.05)$.

(a)

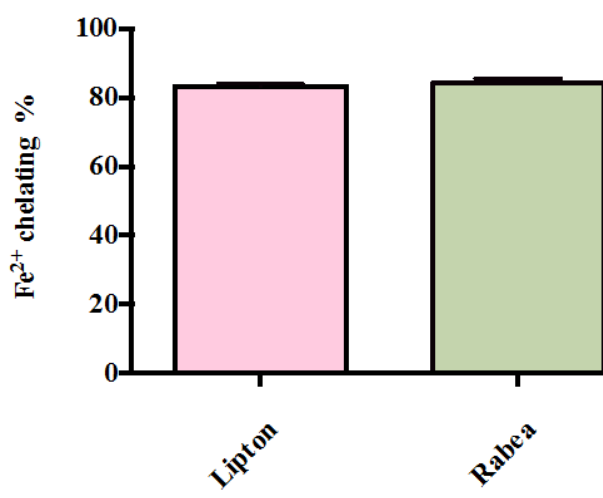

Concentration ( $10 \mathrm{mg} / \mathrm{ml}$ ) (b)

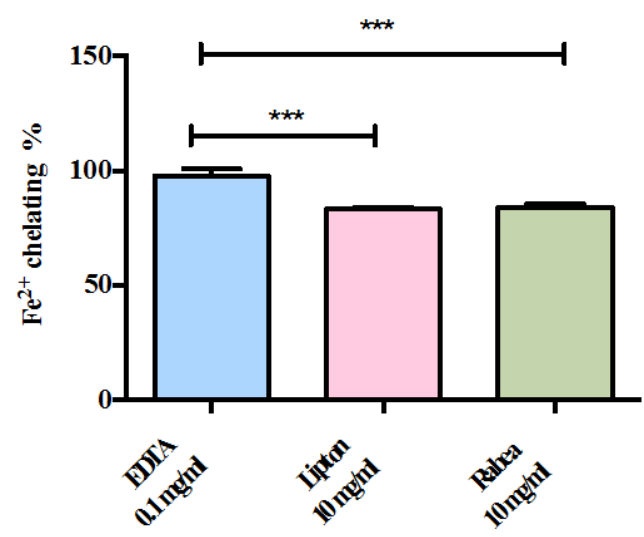

Figure 4. (a) Ferrous ion chelating activity of Lipton and Rabea green tea. Concentration of both components was $10 \mathrm{mg} / \mathrm{ml}$. The value expressed as means \pm SD $(\mathrm{n}=3)$. Compression of means was made using unpaired t-test $(P>0.05)$. (b) Metal chelating activity of EDTA and Lipton and Rabea green tea. Concentration of both components was $10 \mathrm{mg} / \mathrm{ml}$. The value expressed as means $\pm \mathrm{SD}(\mathrm{n}=3)$. Compression of means were made using unpaired t-test $(* * *=P<0.05)$.

fermentation process; catechins in the black tea are reduced as they are converted to the flavins and thearubigins [24].

Moreover, our results showed that the two brands have the ability to scavenge free radicals. A study conducted by [25], indicated that the analysis of DPPH free radicals scavenging ability by green tea showed higher radicals scavenging efficiency than black tea extract. The presence of chlorophyll and pheophitin in green tea extract could explain the higher DPPH scavenging activity in these samples (Figure 1).

Furthermore, our result indicated the presence of high concentration of polyphenols that scavenge $\mathrm{H}_{2} \mathrm{O}_{2}$ in similar way in both brands. The result of [18] was similar to our result. Furthermore, this study is in agreement with [26] findings, which reported that green tea had more activity than herbal tea due to the presence of high concentration of catechin in green tea. Moreover, it was observed in their study that the production of $\mathrm{H}_{2} \mathrm{O}_{2}$ in tea was low as long as hot water is used while preparing tea.

In addition, our results revealed that there was no significant difference in the reducing activity between the two brands $(P>0.05)$. Several studies have shown that green tea had the highest reducing power. One of these studies proved that the extracts of green tea had ability to react with metal ions $\left(\mathrm{Fe}^{3}\right)$ and free radicals by electron donating property [20]. Moreover, green tea in particular showed great significant ferric reducing antioxi- 
dant power (FRAP) values $(P<0.05-0.0001)$ according to the study done by [27]. A possible briefly explanation for this assay might be that due to flavonoid possession of a 2,3-double bond in conjugation with the 4-oxo function in the $\mathrm{C}$ ring and a hydroxyl group adjacent to the $\mathrm{B}$ ring [28].

In this study, the green teas showed high metal chelating activity. In agreement with our results, the study by [28], indicated that tea types with higher catechins content and consequently higher antioxidant activity would also exhibit higher metal chelating activity. The chelating ability of green tea was attributed to the specific chemical groups on its polyphenol structure. Therefore, the presence of hydroxyl and carbonyl groups attached to a molecule or hydroxyl groups among molecules would chelate ferrous ion [28]. It was also reported that the distribution of chemical groups in the molecule that can interact with metal ions, is well known and certain combinations like a 3- and/or 5-hydroxyl group with a C4-keto group in the C ring, or the presence of 3',4'-dihydroxy group located on the $\mathrm{B}$ ring which are considered the major site for metal chelating due to catechol moiety, or a large number of $\mathrm{OH}$ groups. Because ferrous ions are the most effectual pro-oxidants in the food system [29], the high ability of green tea for ferrous-ion chelating could be advantageous, if they were brewed as a drink or formulated into foods.

\section{Conclusion}

Our research work showed that generally green tea has higher content of polyphenols of high biological activity. Moreover, phenolic compounds in both popular green tea brands in Saudi markets (Lipton and Rabea) acted nearly at the similar rate in all five mechanisms, which were tested in this study. These findings enhance our understanding of the extent of the effect of antioxidants against free radicals reactive metal ions by applying some antioxidant methods. Further researches should focus on determining the antioxidant activity in green tea with new supplements by using different mechanisms.

\section{Acknowledgements}

The research team would like to thank Science Research and Innovation Unit in Faculty of Science, King Abdulaziz University, Jeddah, Saudi Arabia, for supporting this work.

\section{References}

[1] Quan, P.T., Hang, T.V., Ha, N.H. and Glang, B.L. (2007) Total Polyphenols, Total Catechin Content and DPPH Free Radical Scavenger Activity of Several Types of Vietnam Commercial Green Tea. Science \& Technology Development, 10, 5-11.

[2] Rabiul Islam, G.M., Gias Uddin, M., Mahfuzur Rahman, M. and Yousuf, A. (2013) Short Communication: Caffeine and Total Polyphenol Contents of Market Tea Cultivated and Processed in Bangladesh. Malaysian Journal of Nutrition, 19, $143-147$.

[3] Reto, M., Figueira, M.E., Filipe, H.M. and Almeida, C.M. (2007) Chemical Composition of Green Tea (Camelliasinensis) Infusions Commercialized in Portugal. Plant Foods for Human Nutrition, 62, 139-144. http://dx.doi.org/10.1007/s11130-007-0054-8

[4] Sangsrichan, S. and Ting, R. (2010) Antioxidation and Radical Scavenging Activities and Tyrosinase Inhibition of Fresh Tea Leaves, Camellia sinensis. Science Journal Ubon Ratchathani University, 1, 76-81.

[5] De la Luz Cádiz-Gurrea, M., Fernández-Arroyo, S. and Segura-Carretero, A. (2014) Pine Bark and Green Tea Concentrated Extracts: Antioxidant Activity and Comprehensive Characterization of Bioactive Compounds by HPLC-ESIQTOF-MS. International Journal of Molecular Sciences, 15, 20382-20402. http://dx.doi.org/10.3390/ijms151120382

[6] Chan, E.W.C., Lim, Y.Y. and Chew, Y.L. (2007) Antioxidant Activity of Camellia sinensis Leaves and Tea from a Lowland Plantation in Malaysia. Food Chemistry, 102, 1214-1222. http://dx.doi.org/10.1016/j.foodchem.2006.07.009

[7] Kusmita, L., Puspitaningrum, I. and Limantara, L. (2015) Identification, Isolation and Antioxidant Activity of Pheophytin from Green Tea (Camellia sinensis (L.) Kuntze). Procedia Chemistry, 14, 232-238. http://dx.doi.org/10.1016/j.proche.2015.03.033

[8] Tran, J. (2013) Green Tea: A Potential Alternative Anti-Infectious Agent Catechins and Viral Infections. Advances in Anthropology, 3, 198-202. http://dx.doi.org/10.4236/aa.2013.34028

[9] Chan, E.W.C., Soh, E.Y., Tie, P.P. and Law, Y.P. (2011) Antioxidant and Antibacterial Properties of Green, Black, and Herbal Teas of Camellia sinensis. Pharmacognosy Research, 3, 266-272. http://dx.doi.org/10.4103/0974-8490.89748

[10] Yim, H.S., Chye, F.Y., Tan, C.T., Ng, Y.C. and Ho, C.W. (2010) Antioxidant Activities and Total Phenolic Content of 
Aqueous Extract of Pleurotus ostreatus (Cultivated Oyster Mushroom). Malaysian Journal of Nutrition, 16, $281-291$.

[11] Adelpilerood, S. and Prakash, J. (2015) Nutritional and Antioxidant Properties of Dehydrated Whole Lime (Citrus latifolia) and Shallot (Allium cepa var. Aggregatum), Two Popular Ingredients Used in Iran. Malaysian Journal of Nutrition, 21, 93-103.

[12] Komes, D., Horžić, D., Belščak, A., Ganić, K.K. and Vulić, I. (2010) Green Tea Preparation and Its Influence on the Content of Bioactive Compounds. Food Research International, 43, 167-176. http://dx.doi.org/10.1016/j.foodres.2009.09.022

[13] Kim, D.O., Chun, O.K., Kim, Y.J., Moon, H.Y. and Lee, C.Y. (2003) Quantification of Polyphenolics and Their Antioxidant Capacity in Fresh Plums. Journal of Agricultural and Food Chemistry, 51, 6509-6515. http://dx.doi.org/10.1021/jf0343074

[14] Bersuder, P., Hole, M. and Smith, G. (1998) Antioxidants from a Heated Histidine-Glucose Model System. I: Investigation of the Antioxidant Role of Histidine and Isolation of Antioxidants by High-Performance Liquid Chromatography. Journal of the American Oil Chemists' Society, 75, 181-187. http://dx.doi.org/10.1007/s11746-998-0030-y

[15] Gulcin, I., Alici, H.A. and Cesur, M. (2005) Determination of in Vitro Antioxidant and Radical Scavenging Activities of Propofol. Chemical and Pharmaceutical Bulletin (Tokyo), 53, 281-285. http://dx.doi.org/10.1248/cpb.53.281

[16] Yildirim, A., Mavi, A., Oktay, M., Kara, A.A., Algur, O.F. and Bilaloglu, V. (2000) Comparison of Antioxidant and Antimicrobial Activities of Tilia (Tilia argentea Desf ex DC), Sage (Salvia triloba L.), and Black Tea (Camellia sinensis) Extracts. Journal of Agricultural and Food Chemistry, 48, 5030-5034. http://dx.doi.org/10.1021/jf000590k

[17] Dinis, T.C., Madeira, V.M. and Almeida, L.M. (1994) Action of Phenolic Derivatives (Acetaminophen, Salicylate, and 5-Aminosalicylate) as Inhibitors of Membrane Lipid Peroxidation and as Peroxyl Radical Scavengers. Archives of Biochemistry and Biophysics, 315, 161-169. http://dx.doi.org/10.1006/abbi.1994.1485

[18] Özyürek, M., Bektaşoĝlu, B., Güçlü, K., Güngör, N. and Apak, R. (2010) A Novel Hydrogen Peroxide Scavenging Assay of Phenolics and Flavonoids Using Cupric Reducing Antioxidant Capacity (CUPRAC) Methodology. Journal of Food Composition and Analysis, 23, 689-698. http://dx.doi.org/10.1016/j.jfca.2010.02.013

[19] Bolanos de la Torre, A.A.S., Henderson, T., Nigam, P.S. and Owusu-Apenten, R.K. (2015) A Universally Calibrated Microplate Ferric Reducing Antioxidant Power (FRAP) Assay for Foods and Applications to Manuka Honey. Food Chemistry, 174, 119-123. http://dx.doi.org/10.1016/j.foodchem.2014.11.009

[20] Oh, J., Jo, H., Cho, A.R., Kim, S.J. and Han, J. (2013) Antioxidant and Antimicrobial Activities of Various Leafy Herbal Teas. Food Control, 31, 403-409. http://dx.doi.org/10.1016/j.foodcont.2012.10.021

[21] Andjelković, M., Van Camp, J., De Meulenaer, B., Depaemelaere, G., Socaciu, C., Verloo, M. and Verhe, R. (2006) Iron-Chelation Properties of Phenolic Acids Bearing Catechol and Galloyl Groups. Food Chemistry, 98, 23-31. http://dx.doi.org/10.1016/j.foodchem.2005.05.044

[22] Stewart, A.J., Mullen, W. and Crozler, A. (2005) On-Line High-Performance Liquid Chromatography Analysis of the Antioxidant Activity of Phenolic Compounds in Green and Black Tea. Molecular Nutrition \& Food Research, 49, 5260. http://dx.doi.org/10.1002/mnfr.200400064

[23] Sabouri, S., Geng, J. and Corredig, M. (2015) Tea Polyphenols Association to Caseinate-Stabilized Oil-Water Interfaces. Food Hydrocolloids, 51, 95-100. http://dx.doi.org/10.1016/j.foodhyd.2015.04.034

[24] Carloni, P., Tiano, L., Padella, L., Bacchetti, T., Customu, C., Kay, A. and Damiani, E. (2013) Antioxidant Activity of White, Green and Black Tea Obtained from the Same Tea Cultivar. Food Research International, 53, 900-908. http://dx.doi.org/10.1016/j.foodres.2012.07.057

[25] Gramza, A., Pawlak-Lemanska, K., Korczak, J., Wasowicz, E. and Rudzinska, M. (2005) Tea Extracts as Free Radical Scavengers. Polish Journal of Environmental Studies, 14, 861-867.

[26] Aoshima, H., Hirata, S. and Ayabe, S. (2007) Antioxidative and Anti-Hydrogen Peroxide Activities of Various Herbal Teas. Food Chemistry, 103, 617-622. http://dx.doi.org/10.1016/j.foodchem.2006.08.032

[27] Taheri, M., Giahi, M., Shahmohamadi, R., Ghafoori, H., Aghamaali, M.R. and Sariri, R. (2011) Screening Antioxidant Activity of Extracts from Different Tea Samples. Pharmacologyonline, 2, 674-683.

[28] Lin, S.D., Liu, E.H. and Mau, J.L. (2008) Effect of Different Brewing Methods on Antioxidant Properties of Steaming Green Tea. LWT_Food Science and Technology, 41, 1616-1623. http://dx.doi.org/10.1016/j.lwt.2007.10.009

[29] Wang, T., Jónsdóttir, R. and Ólafsdóttir, G. (2009) Total Phenolic Compounds, Radical Scavenging and Metal Chelation of Extracts from Icelandic Seaweeds. Food Chemistry, 116, 240-248. http://dx.doi.org/10.1016/j.foodchem.2009.02.041 